\section{APPLICATION OF GREEN SYNTHESIS OF GOLD NANOPARTICLES: A REVIEW}

\author{
Adamu Ibrahim Usmana,c, Azlan Abdul Aziza*, Osama Abu Noqta \\ aSchool of Physics University Sains Malaysia, 11800, Pulau Pinang, \\ Malaysia \\ bInstitutes for Research in Molecular Medicine. USM, 11800, Pulau \\ Pinang, Malaysia \\ cDepartment of Physics, Federal University Kashere, Nigeria
}

Article history

Received

1 August 2017

Received in revised form

28 September 2018

Accepted

15 October 2018

Published online

15 December 2018

*Corresponding author
lan@usm.my

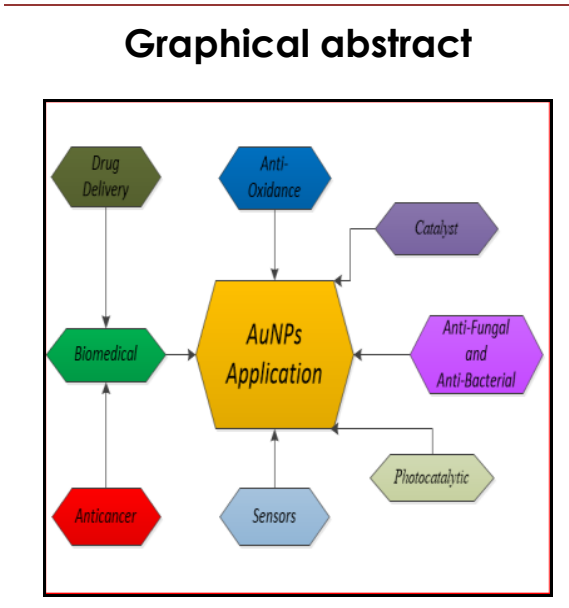

\begin{abstract}
The field of nanotechnology is advancing rapidly due to its extensive applications in distinct fields of science and technology. Several methods have been used for the production of nanoparticles due to their immense functions in various fields. The limitations of the traditional methods and their toxic nature of the chemicals used during the synthesis or in their application hinder their usage in the biomedical field. This led to the development of the green synthesis of nanoparticles. Researchers have focused on developing simple, cost-effective, clean, non-toxic and eco-friendly procedures for synthesis of nanoparticles. Various biological agents like bacteria, fungi, plant extracts, etc. are used for the green synthesis of metal nanoparticles due to their biocompatibility. The dissolved metals ions are reduced into nano-metals by bio-agent in the green process. The manners and protocols of the green synthesis of gold nanoparticles are presented in this review. Recent literature on green synthesis of noble gold nanoparticles with their various applications in biomedical, antifungal/antibacterial, drug delivery, sensors and photocatalytic have also been discussed.
\end{abstract}

Keywords: Application, gold, nanoparticles, green, review

\begin{abstract}
Abstrak
Bidang nanoteknologi sedang berkembang pesat kerana penerapannya yang luas dalam bidang sains dan teknologi yang berbagai. Beberapa kaedah telah digunakan untuk penghasilan nanopartikel kerana fungsi mereka yang besar dalam pelbagai bidang. Batasan kaedah tradisional dan sifat toksik bahan kimia yang digunakan semasa sintesis atau dalam aplikasi menghalang potensi penggunaannya dalam bidang bioperubatan. Ini membawa kepada pembangunan sintesis hijau nanopartikel. Penyelidik sekarang sedang menumpukan pada pembangunan prosedur mudah, kos efektif, bersih, tidak toksik dan mesra alam untuk sintesis nanopartikel. Pelbagai agen biologi seperti bakteria, kulat dan ekstrak tumbuhan digunakan untuk sintesis hijau logam nanopartikel kerana sifat keserasian-bio yang wujud. Kajian komprehensif ini membentangkan kaedah dan protokol terkini untuk sintesis hijau nanopartikel emas. Perbincangan utama adalah mengenai ion logam terlarut yang dikurangkan menjadi nano-logam oleh agen-bio dalam proses hijau. Persuratan terkini mengenai sintesis hijau nanopartikel emas nobel bersama pelbagai aplikasi mereka dalam bioperubatan, antikulat /antibakteria, penghantaran ubat, sensor dan foto pemangkin turut dibincangkan.
\end{abstract}

Kata kunci: Permohonan, emas, nanopartikel, hijau, semakan

(c) 2019 Penerbit UTM Press. All rights reserved 


\subsection{INTRODUCTION}

Nanostructures and nanotechnology is a broad and interdisciplinary area of research and development activity that has growth explosively globally in the last few decades [1]. Recently, world evaluation of current innovations shows much curiosity in the field of nanotechnology. This curiosity resulted from many unique physical and chemical properties of materials in the nanoscale level, such as a large surface-tovolume ratio and the increase in surface activity as correlated to their bulk materials with the same composite. These authorize their use in catalysis, antibacterial, anticancer, drug delivery as well as mechanical and optical applications [2]. Many traditional techniques have been employed in the synthesis of nanoparticles such as microwave irradiation [3], laser ablation [4] solid-state reaction [5], gas phase condensation [6], liquid phase chemical precipitation [7], surfactant assistant liquid-liquid reaction [8], spray pyrolysis [9], solvothermal [10], thermal decomposition of single source precursor [11], thermal reduction [12], ultrasound [13] and so on. These techniques are based on the reduction of metallic ions with conventional stabilizing and reducing agents such as sodium dodecyl sulfate, sodium citrate, sodium borohydrate, which are quite expensive. Furthermore, these materials are potentially hazardous to the environment, and their usage is a threat to human health since a small amount of these reagents remain free and non-reactive in the mixture. The entrance of these reagents into the environment and human tissue results in environmental pollution and damage to several tissues respectively [14]. The process of employing natural bio-agents such as plant extracts, sugars, fungi, biodegradable polymers, bacteria, etc., as stabilizing and reducing agents for synthesis of inorganic nanoparticles could be deliberated as a new method to overcome the mentioned drawbacks [15-17]. Green system for biosynthesis of noble metal nanoparticles has numerous benefits over traditional chemical methods [18]. These include, eco-friendly, easy, and cheap bioresources; does not require the use of high temperature or pressure; does not consume hazardous or toxic materials; does not require any synthetic ligand, capping or stabilizing agent for the biosynthesis of nanoparticles.

Gold nanoparticles (AUNPs) have been widely recognized for various applications such as catalysis, electronics, photonics, sensing, catalysis, antibacterials, biomedical or drugs delivering agent for curing cancer ranging from chemical pollutants to biomolecules [1721]. These applications are suitably applied based on the AuNPs properties especially their size and morphology. It is known that AuNPs produced by chemical methods are generally spherical [22], which confine their applications. Though, various methods have produced AuNPs with different morphology such as nanospheres, nanorods, nanowires, nanoporous, nanotriangle, and nano caps [23-25]. However, controlling the shapes with confined size is possible to some extent [26]. The capability to control the morphological (size, shape, and crystalline structure) of AuNPs during production has some substantial role in various fields of application. Recently researchers focused on the green synthesis of AuNPs for various application, which requires new approaches for the assembly and synthesis of nanoparticles (NPs) in large number with control size. This review focuses on current and emerging roles of a green system for the synthesized AuNPs using biodegradable materials and their applications.

\subsection{METHODOLOGY}

\subsection{General Method for the Synthesis of Metals Nanoparticles}

Stabilized noble metal NPs have been produced using several methods. These methods are primarily classified into bottom-up and top-down process (Figure 1). In the bottom-up method, nanosized assemblies were formed by molecular components. Whereas, in the top-down method, nanoparticles are generated from their constituent metals with the helped of the reserved microscopic machine and converted into nanoscale dimensions [28]. The bottom-up process is one of the common and efficient techniques of obtaining NPs with moderate imperfection, less Gibbs free energy and similar chemical structure [29]. Production of noble NPs via chemical reduction in the presence of metal salt precursors as reducing agents such as sodium borohydride [30] and sodium citrate [31] got appreciable attention of the researchers and had been widely employed in various research activities. The absence of the repulsive forces between the two NPs due to small mean distance presence between them led to strong attraction between them with the impact of van der Waals forces. Therefore, aggregation will be generated [32], a wider range of capping or stabilizing agent will be required to prevent the agglomeration, stabilized and extended the shelf-life period of the NPs. 


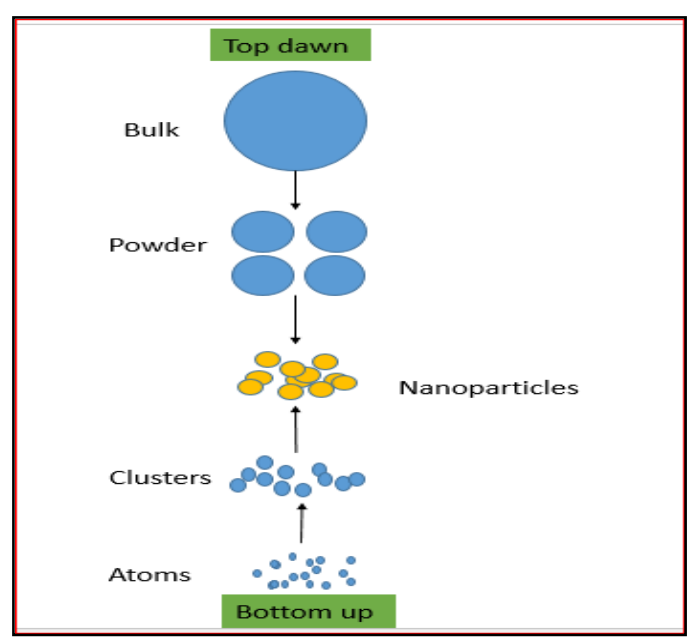

Figure 1 Procedures employed in the synthesis of nanoparticles using bottom up and top down process

\subsection{Systematics Steps for Bioreduction of Gold Nanoparticles}

Bioreduction of AuNPs are obtained via either plant tissues or microorganisms. Employing plants tissue in the bioreduction process of AuNPs, the plants part are unsoiled with distilled water, dried, grind into powder or cut into small units and heated in a distilled water to a certain temperature to obtain a liquid extract. Filtration or centrifugation techniques or both are used to separate the filtrate from the residue, and the purified filtrate will be kept at $4{ }^{\circ} \mathrm{C}$ for further used. In the case of microorganism, an enrichment culture is developed by growing a mixed population culture in a semi-synthesis medium under specific anaerobic condition. Then a simple organism will be isolated from the established culture by subsequent serial subculturing of the enrichment culture whereby the same state will be maintained as in enrichment culture. Then the pure microorganism will be obtained by proper filtration. The microorganism or extract will be mixed with the chloroauric salts solution (at various concentrations base on microorganism or plants parts) at the particular condition. Their growth into NPs occur within minutes in a single step and eco-friendly process, this is represented by our simple diagram (Figure 2). External stabilizing/capping agents will not be added since phytochemicals act as both stabilizing and reducing agents. The solution is then induced to transform the metal salt into NPs usually detected by colour change and finally, the NPs were formed.

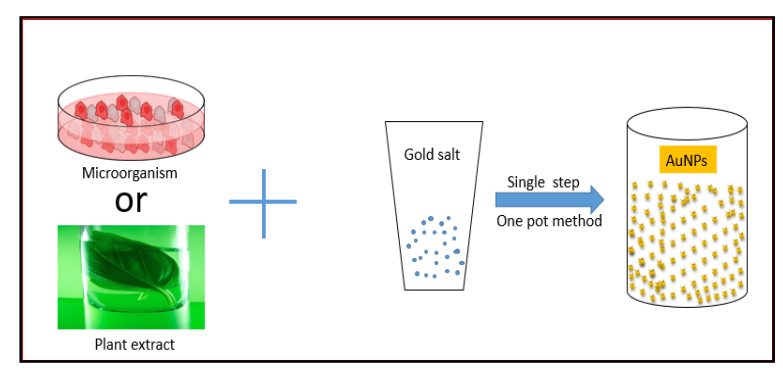

Figure 2 simple process for the synthesis of gold nanoparticles using microorganism or plant extracts

\subsection{Stabilization Process of Metal Nanoparticles}

Stable metal NPs are obtained with the aid of stabilizing agent which mostly maintained a repulsive force that is against the van der Waals forces in a solution phase [33]. Likewise, steady and soft reducing agents like sodium borohydride or sodium hydride [34] and sodium citrate or ascorbic acid give control over the size and shape of metal NPs in conventional chemical synthesis respectively. Whereas, in the green synthesis, the functional group in the bio-agent such as primary amine, alkene, alcohol polyphenol, carboxylic and surfactant presence in protein [35] may likely offer the control, and could also be controlled by varying the concentration of metal salt precursors, $\mathrm{pH}$, and temperature. Stabilizing agents, preserve the metal NPs by calmly relating with them, by averting the agglomeration of NPs. The mechanism for stabilization of metal NPs had been explained in Derjaguin Landau Verwey Overbeek theory (DLVO) $[36,37]$. There are three different categories of stabilization of metal NPs using capping agents: (I) steric stabilization (II) electrostatic stabilization, and (III) unification of steric and electrostatic stabilization [38].

\subsubsection{Electrostatic Stabilization}

In this stabilization, an electric double layer which results from the presence of both repulsive forces and van der Waals forces between the NPs by the action of some ionic composite. These include polyoxoanions, carboxylates, and fluorides. The electrostatic repulsions prevent the occurrence of aggregation in the solution phase and influenced by some substantial variables such as concentration, $\mathrm{pH}$, and temperature [39].

\subsubsection{Steric Stabilization}

Free motion of metal NPs during synthesis is restricted in this type of stabilization. Functional groups such as alcohol, surfactants, different oligomers or polymers are utilized in this kind of stabilization. A protective layer will be created by the assimilation of the particles at the outer surface of NPs, which 
performed a significant action in the stability of metal NPs [40].

\subsubsection{Unification of Steric and Electrostatic Stabilization of Metal NPS}

This type of stabilizations maintained metallic NPs stability in solution phase. An Ionic surfactant with long chain ends and polar head group generates electric double layer around the NPs and provides steric repulsion within the NPs, this lead to mutual stabilization system [41].

\subsection{VARIOUS APPLICATIONS OF GOLD NANOPARTICLES SYNTHESIZED VIA BIOAGENT}

\subsection{Catalyst}

In the presence of a catalyst in any reaction, low free energy is required to reach the transition state for the complete reaction to occur, for the total free energy of the reactant and products to remain the same. The effect of the catalyst may vary due to the presence of other substances known as inhibitors or promoters. This increased the activities of the enzyme but does not take part in the reaction and may be deactivated by a secondary process [42]. The demand for catalyst in various activities, especially in the potential non-toxic application or fuel cell application leads to the biosynthesis of AuNPs. These NPs are produced using bioagent materials instead of synthetic materials, whereby the surface of AuNPs can be utilized in selective oxidation.

Green technology, which is eco-friendly and environmentally safe has been developed by Guria et al. to synthesize AuNPs using culture filtrate of Fusarium sp. MMT1 strain [43]. The mean diameter of AuNPs was found to be $30.61 \pm 17 \mathrm{~nm}$, the TEM image and AFM profile of biosynthesized AuNPs show that most of the particles are spherical. Although, various structures of hexagonal, triangular, and rod-shaped distribution was also observed. The manifestation of a $\sim 60 \mathrm{kDa}$ protein on the AuNPs surface accomplished higher stability and controlled agglomeration. The fungal-based bioreduction of nanocatalyst shown effective reusable catalytic action for the transformation of noxious o-nitrophenol, onitroaniline, and p-nitrophenol. The major contribution of their work is the accomplishment of reserved nanocatalyst after used. This effectively transforms nitroaromatics at an absorption hundred times greater than the previous studies [44-48]. In a study by Ahmad et al. [49], AuNPs was synthesized using Salicornia brachiata (Sb), and estimation of their catalytic and antibacterial application was investigated. The characteristic of the surface plasma resonance (SPR) peak of SbAuNPs at $532 \mathrm{~nm}$ showed a purple colour (Figure 2). Various polydispersed shape and sizes range from $22 \mathrm{~nm}$ to $35 \mathrm{~nm}$ of the prepared AuNPs were measured using
SEM and TEM respectively. In a similar study by Qu at al. [50]. Afresh biosynthesis of AuNPs were developed with potential application in azo dye decolorization using isolated strain Trichoderma sp. as bio-agent. Various parameters like $\mathrm{pH}$, the concentration of precursor and biomass were altered to obtain optimal condition. $1 \%$ and $5 \%$ of Plumeria alba flower extract (PAFE) were used to synthesized AuNPs with an average size of $28 \pm 5.6$ and $15.6 \pm 3.4$ respectively [51]. The synthesized AuNPs played the role of base acting catalyst.

In a study by Kumar and his group, AuNPs were synthesized using Sacha inchi oil as stabilizing agent and capping agent via sunlight [52]. The assynthesized AuNPs are about 5 to $15 \mathrm{~nm}$ in size, monodispersed in this case with non-aggregated shape, spherical and crystalline these were confirmed by morphological and spectroscopic analysis. The resulted NPs were accountable for the efficient photocatalytic reaction. The proposed method is rapid, highly promising, and quickly applied in catalytic activities. This indicates another means to take over the expensive anxious chemicals in large scale production [53]. Plant extract of Eucommia ulmoides was assessed for the growth of AuNPs with a mean size of $16.4 \mathrm{~nm}$ and $18.2 \mathrm{~nm}$ via TEM and DLS respectively. This difference is that TEM measured the actual size of the particles size, while the DLS measured the surrounding shadow of the particles size known as hydrodynamical size.

For the first time a complete production of AuNPs with an average size of $2.3 \mathrm{~nm}$ by the entirely green approach of reducing $A \cup(I I I)$ with chitosan subordinate (biocompatible, nontoxic N-(4imidazolyl) Methyl Chitosan (IMC)) as stabilizing and reducing agents to synthesize AuNPs. But the reduction of $A \cup(I I I)$ to AuNPs in IMC solution is a slow process in which the coordination power of biopolymer controls both reducing species concentration and gold crystal growth rate. Also, the AuNPs growth in IMC solution do not manifest SPR but display luminescence at $375 \mathrm{~nm}$ under UV light excitement at $230 \mathrm{~nm}$ [54]. In a similar investigation, Moringa oliefera was used to synthesize $<5 \mathrm{~nm}$ of AuNPs [55]. Shell extracts from Mung bean starch (MBS) [56], Abroa ma Augusta Linn [57] and green coconut (Cocos nucifera Linn) [58] were utilized in gold chemistry and synthesis of AuNPs at room temperature under the mild condition without adding any extra stabilizing or capping agents as reducing or stabilizing agents respectively. These prepared AuNPs were used as a heterogeneous catalyst in the reduction of 4-nitrophenol (4-NP) in the presence of sodium borohydride $\left(\mathrm{NaBH}_{4}\right)$.

Physiological properties of three aqueous plant extracts (Mentha piperita, Melissa officinalis, and Salvia officinalis) were compared and optimized under standardized conditions in the growth of AuNPs by Dzimitrowicz and his team. The effects of the concentrations of the precursor, plant extract, and the reaction temperature on the production and morphology of the synthesized AuNPs were 
examined using UV-Vis, DLS, TEM, and SEM [59]. Lagerstroemia speciosa leaf extract was used in the green synthesis of AuNPs within 30 minutes at $25^{\circ} \mathrm{C}$, and the same results were obtained within 2 minutes at elevated temperature of $80^{\circ} \mathrm{C}$ [60]. The bark extract of Saraca indica containing redox active polyphenolic compounds was used to reduced gold salt to AuNPs at ambient temperature. The functional group such as polyphenolic present in the extracts served as both reducing and stabilizing agent. An average particles size of 15 to $23 \mathrm{~nm}$ of AuNPs was obtained in a few minutes and no any heat treatment or photoirradiation was involved [61]. On the other hand, leaf extract of Pogestemon benghalensis was used to synthesized AuNPs, and the process was completed in $12 \mathrm{~h}$. The resulted NPs were characterized using XRD and UV-Visible spectroscopy. The XRD pattern indicated that the production of the face-centered cubic structure of gold having a wavelength of $555 \mathrm{~nm}$ with an average crystallite size of $13.07 \mathrm{~nm}$. These NPs also exhibit catalytic activities.

\subsection{Antibacterial}

Antibacterial is also known as antibiotic, is a type of antimicrobial drug used in the prevention and treatment of bacterial contamination which may either kill or inhibit the growth of bacteria [62]. Gold nanoparticles synthesized via green methods showed antibacterial activities in various fields.

A marine bacterial isolate (Streptomyces sp.) was utilized in the biosynthesis of AuNPs as reducing and stabilizing agents, and chloroauric acid (HAuCl4) as a precursor in a study by Ibrahim et al. [63]. The antibacterial activity was achieved by surface reformation of viscose and cotton woven fabrics via $\mathrm{O}_{2}$-plasma. This was pursued by additional manipulation with bioreduction of AuNPs alone with ZnONPs or $\mathrm{TiO}_{2} \mathrm{NPs}$ with UV-blocking. In a similar study, Acorus calamus rhizome served as a reducing agent, and the antibacterial activities were achieved without addition of any binder. The authors reported that the hydroxylic group present in the extracts might stabilize the surface of the cotton coated with the AuNPs [64]. Sound antibacterial activity was revealed by coating the designated NPs on the mobilized fabric specimens against both $G$-ve ( $E$. coli) and $G+v e$ (S. aureus). It also revealed a unique increased in the UV-cover performance of the manipulation fabrics. The highest anti-UV values and antibacterial were determined when $\mathrm{O}_{2}$-plasma fabrics were combined with AuNPs/ZnONPs, irrespective of the substrates used. A new route for bio-functionalization and coloring of various fabrics with green technologies were tested against skin pathogen and Brevi bacterium linens using LIVE/DEAD BacLight [65]. Accordingly, this should open new avenues for innovation in the textile and garment sectors (Figure 3). Moderate antibacterial activity was reported when aqueous gold ions were exposed to Salix alba L. leaves extract. The resulted biosynthesized AuNPs have size range from 50 to 80 $\mathrm{nm}$ [66] and displays excellent antifungal activities against $A$. solani, A. niger and A. flavus.
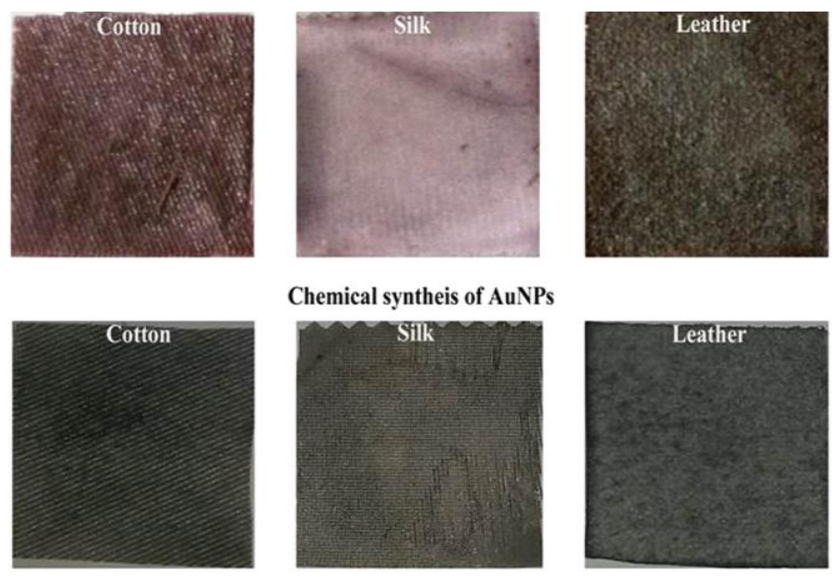

Composite of green and chemical synthesis of AuNPs
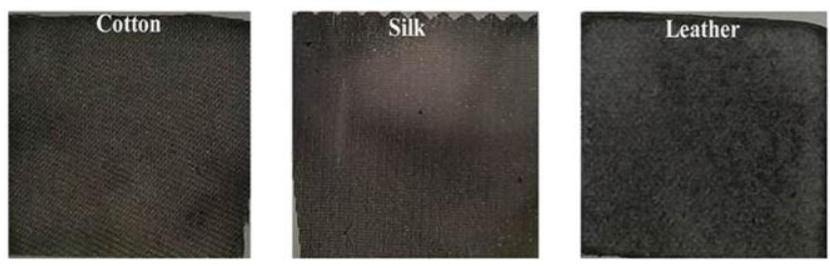

Figure 3 Visual image of cotton, silk and leather fabrics dyed with different treatment methods [65]

\subsection{Drug Delivery and Anticancer}

The efficiency and effectiveness of drugs depend on the target specificity and its solubility. Adverse drug reactions need to be associated with extra doses to treat diseases in a human cell. Emerging NPs have deviated from conventional therapies like chemotherapy, radiation, and surgery. Gold and silver NPs are among novel NPs, which have emerged as potential contributors in delivering different kinds of drug molecules at target sites controllably and sustainably [67]. Gold nanoparticles, in particular, attracted the attention of so many researchers due to their prospects in cancer therapy and the treatment of other ailments.

Genipa Americana L. fruit extract was successfully used in the growth of AuNPs by Kumar and his coworkers [68]. Functional groups in the extracts such as geniposide, genipaol, ranolazine, and genipin were the agents that stabilized the synthesized AuNPs as confirmed by electrospray ionization mass spectrometry (ESI-MS) and FT-IR spectroscopic. Under ambient temperature, the AuNPs are stable for more than six months and free from toxic chemical compounds. It effectively tested against HeLa cancer cell and A-549, from cervix and lung. Rajan and his group reported the environmentally benign synthesis of AuNPs of an average particles size of 15.2 $\mathrm{nm}$ using the aqueous extract of Elettaria cardamomum seeds [69]. The as-synthesized AuNPs 
exhibited antibacterial activity against a broad spectrum of bacterial pathogens and showed excellent cytotoxic performance towards HeLa cancer cell lines. A special active AuNPs against cancer cells with sizes 70 - $90 \mathrm{~nm}$ particles were synthesized by using Diospyros ferrea. As a result of a wide survey on the utilization of newly synthesized AuNPs, their anticancer potentiality was discovered using the MTT assay [70]. In a similar study, Vitex negundo leave extract was used in the presence of sunlight and Arabic gum as a stabilizing agent to produce AuNPs. The folic acid found in the extracts was used in functionalizing the synthesized AuNPs for drug delivery in terminating tumor [71]. Various extract of Rhus chinensis of Chaga mushroom [72], Sargassum glaucescens [73], chitosan oligosaccharide [74], Fucoidan [75], and cassia tora extract [76] were effectively utilized as bioagent for the bioreduction of AuNPs, which were applied in the treatment of the cancer cell. The morphology, sizes and crystal structures of the synthesized AuNPs were examined using AFM, SEM-EDX, SEM, TEM, FT-IR, and UV-Visible spectroscopy (Figure 4).

\subsection{Biomedical Application}

A negative electric charge AuNPs with an average size of $26 \pm 11 \mathrm{~nm}$ without aggregation were produced using fruit extract of Couroupita guianensis Aubl as a possible bio-reductant to reduce $\mathrm{Au}^{3+}$ ions into their nanoscale. DLS and EDAX results were used to prove that the synthesized AuNPs were free from contaminants and they were stable [77]. 21 different types of infinitesimal fungi were randomly selected based on the experimental parameters and exact class of microorganisms by Vágó at el [78], to produce highly stable AuNPs with various morphology and sizes. Out of 21, 20 cell-free extracts of fungi were successfully used to produce AuNPs as revealed by spectroscopic and electron microscopic measurements. Aqueous gold metal ions was reduced to AuNPs in the presence of aqueous peel extract of Garcinia mangostana. Mostly, the NPs produced are spherical with a mean diameter of $32.96 \pm 5.25$. The FTIR results indicated that the peaks obtained are roughly similar to flavonoids, phenols, anthocyanins, and benzophenones, which are the potential reducing agent to produced AuNPs [79]. Similarly, an extract of cassava starch, was employed to synthesize AuNPs with size ranges from 15 to $35 \mathrm{~nm}$ and L-cysteine was used in functionalizing the assynthesized AuNPs and no shape deformation was observed. The functionalized AuNPs were effectively improved xylanase functionality [80]. Acquires extracts of Stevia rebaudiana (SR) was employed for the synthesis of AuNPs by Sadeghi et al. with sizes ranges from 5 to $20 \mathrm{~nm}$ [81]. Furthermore, the plant extract of Stachys lavandulifolia Vahl was utilized in producing AuNPs with standard stability. The stability of the NPs was compared with conventional citratecapped NPs, under both synthetic and physiological conditions [82]. Moringa oleifera leaf extract was used as a reducing agent in synthesizing AuNPs with a size range between $20-60 \mathrm{~nm}$ [83]. These NPs were applied for biomedical applications.

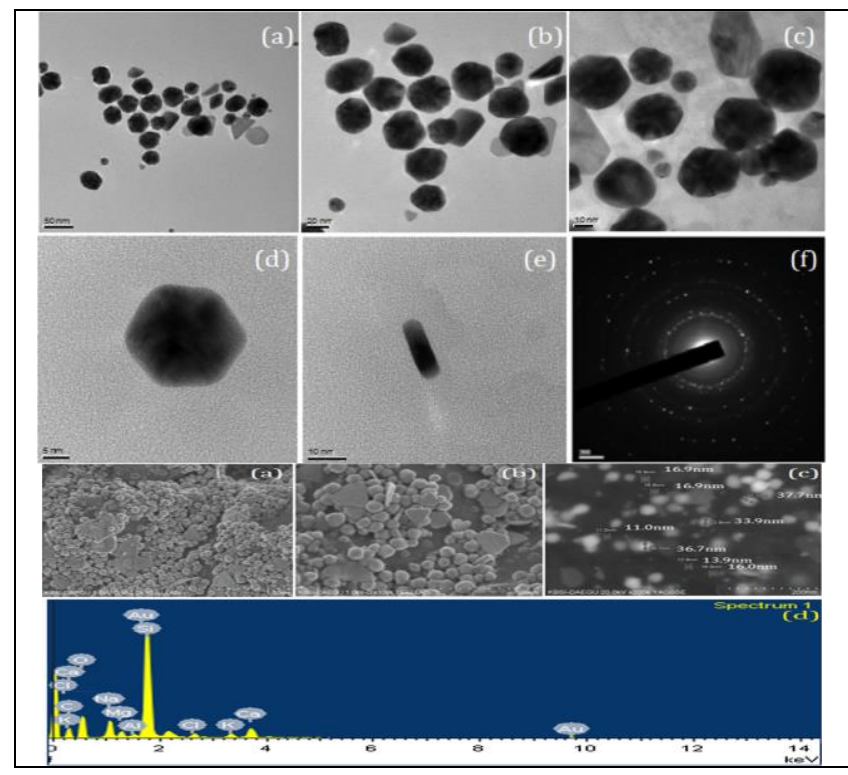

Figure 4 TEM (a-e) f-SAED from left and SEM (a-c) d-EXD from the right profile of green synthesis of AuNPs using Chaga mushroom [72]

In research by Yang and Li, AuNPs were synthesized using Chitosan oligosaccharide as bioagent. Their results revealed that the average size of the particles was $115.217 \pm 16.87 \mathrm{~nm}$ and the particles were used against human fibroblast [84]. Proanthocyanidin was used for the design and development of biocompatible AuNPs for subsequent usage in medical applications by Vinodhini at el [85]. Bio-reduction of chloroauric acid into AuNPs was observed when treated with active bio-component from cassia auricualta flower within three minutes with particles sizes ranges from 12 to 41 $\mathrm{nm}$ [86]. Turbinaria conoides was used also, in the green synthesis of AuNPs with particles sizes ranges from 6 to $10 \mathrm{~nm}$ by Rajeshkumar and his group [87]. An aqueous liquid extract of black cardamon solution was mixed with $\mathrm{HAuCl}_{4} \cdot 3 \mathrm{H}_{2} \mathrm{O}$ solution. Whereby, 1,8-cineole is the assertive character that acts as stabilizing and reducing agent to synthesized AuNPs with an average particles size of $50 \mathrm{~nm}$ [88]. Leaf extract of Mentha piperita was used as a stabilizing agent for the synthesis of AuNPs. The results were optimized by varying the concentration of the leaf extracts, temperature and time. $1.5 \%$ of leaf extracts at $70{ }^{\circ} \mathrm{C}$ for $1-3$ minutes was found to be the best-optimum condition for bioreduction of AuNPs. Then followed by using $1 \%$ extracts at $90{ }^{\circ} \mathrm{C}$ for 5 minutes. The morphology of the particles were mostly spherical and triangular with diameter ranges between 3 to $26 \mathrm{~nm}$. Mentha piperita leaf extract [89] and peltophorum pterocarpum flower extracts [90] were used in a rapid way to synthesized AuNPs 
with low toxicity, which could be potentially applied in biomedical. However, most of the authors claim that the AuNPs will be applied in the Biomedical application without mentioning a specific type of application.

\subsection{Sensor}

A sensor is a device which receives data or information by detecting an event or changes in the environment of the real world and transferred the data in coded form into the computer to generate the desired output. Green technology has busted the utilization of AuNPs as a potential candidate in sensor application. They will be applied beyond the conventional (temperature, pressure, and flow measurements), but into daily activities and in industries. These include medicine, robotics, cars, airplanes and aerospace, machinery and various daily activities. Below is the recent report on biosynthesis AuNPs and their detection ability.

Isolated Patuletin from Tagetes patula was used as a reducing as well as capping agent to synthesize AuNPs capped with patuletin. FT-IR and UV-visible spectroscopy was used in confirming the conjugation of gold with patuletin and $63.2 \%$ by weight of patuletin was found to be conjugated to gold nanoparticles with an average size of $45 \mathrm{~nm}$ measured using AFM. Fourteen distinct drugs were used in investigating the potentiality of the assynthesized AuNPs as a chemical sensor. Positive results were obtained in all cases except in the case of piroxicam, which quenched luminescence [91]. An environmentally toxic contaminant (hydrazine), which shows an extensive linear range of 5 to $272 \mathrm{nM}$ with a lower detection limit of 0.05 IM was successfully detect using AuNPs produced with Cerasus serrulata leaves extract. The Cerasus serrulata leaves extract served as both stabilizing and reducing agent. The biosynthesized AuNPs were spherical with particles sizes range from 5 to $25 \mathrm{~nm}$ [92]. In a different study by Barabadi and his team, Penicillium aculeatum was used to synthesized AuNPs, and their scolicidal activity against hydatid cyst protoscolices of Echinococcus granulosus was investigated [93]. While, Acacia nilotica twig bark extract was used in trace level detection of one of the hazardous materials, viz. nitrobenzene (NB) that causes Methemoglobinaemia at room temperature in 10 min [94]. Graphene oxide embellishes with AuNPs using rose water as a stabilizing agent have revealed positive reaction to glucose with direct extent from 1 to $8 \mathrm{mM}$ with low detection limits of $10 \mu \mathrm{M}$ [95]. Copper ions in aqueous solution and spiked serum samples were detected using bioinspired AuNPs synthesized using Gordonia amarae aggregated in the presence of cysteine as reducing and stabilizing agents [96].

\subsection{Antioxidant}

An antioxidant is a molecule that exhibits the oxidation of other molecules. Oxidation is a chemical reaction that produces free radicals, leading to the chain reactions that may damage the body cells. Such antioxidants like ascorbic acid or thiols terminate these chain reactions to balance the plants and animals oxidative state and maintain complex systems of overlapping. This is an internal production, which leads to reversing and protecting the damage caused by oxidation to some extent [97]. These attract the attention of some researchers to synthesize AuNPs from bioagent materials to test its functionality in antioxidants.

Eco-friendly and bioinspired techniques to synthesis AuNPs for the effective antioxidant capacity was developed by a research group headed by Tahir [98]. Nerium oleander leaf extract was used as bioagent to synthesis the AuNPs with particles sizes from 2 to $10 \mathrm{~nm}$. The MPs obtained were mostly spherical and highly dispersed without any aggregation. Multiple twinned quasi-spherical and prismatic shapes NPs were synthesis with Acroscyphus $\mathrm{sp}$. and Sticta sp. respectively and the biomatrix loaded AuNPs exhibited antioxidant activity. Also, Sambucus nigra L. extract shows great potential in the diabetic treatment due to the development of antioxidant defense and reduction of MMPs reaction and their manipulation in liver cells [99]. Various bioagent were employed in the synthesis of AuNPs such as novel probiotic Lactobacillus kimchicus DCY51T isolated from Korean kimchi via an intracellular membrane-bound mechanism [100], Piper longum fruit extract [101], Pterocarpus marsupium [102], Garcinia Cambogia [103]. The resulted AuNPs in all cases showed effective antioxidant activities.

\subsection{CONCLUSION AND FUTURE PROSPECTS}

Nanotechnology is an extremely growing area of study due to its wide range of utilization in distinct fields of research. Several techniques have been employed for the synthesis of AuNPs, which are mostly conventional chemical methods. However, these methods have some substantial restrictions in the form of a toxic chemical used during the production or later in their applications. The disposal process of the toxics reducing agent used in the synthesis of AuNPs is not easy because of environmental concern. Consequently, higher temperatures are required in some process, which produces a large amount of heat and can lead to the generation of AuNPs that are very expensive. The green techniques used to prepare AuNPs have attracted the efforts of many researchers. This is due to its economic custom, rapid, and non-infirmity nature to produce in a simple step process at normal atmospheric pressure and room temperature. The biological reduction process of AuNPs utilized various 
plant tissues and microorganism that are environmentally safe when compared with ordinary chemical methods. The above mentioned AuNPs synthesized using various bioagent are summarized in table 1 with their various sizes and applications. Presently, investigation on bioreduction of gold nanoparticles is an uncovering aspect. So many problems need to be solved and identified. There is a need to conduct many experiments to comprehend the effects of temperature, amount of concentration of reducing agent, light, time, etc., on the synthesis of AuNPs and optimized the as-synthesized nanoparticles. The optimization process should consider the interaction and quadratic effects of the individual variables under consideration. Furthermore, knowledge of chemical composite and the mechanism for the transformation and stabilization of bioreduction of AuNPs are still questions under investigation. Therefore, additional research and analysis are proposed to address the mechanism of production of AuNPs and effect on morphology and size of AuNPs for various applications.

In conclusion, this paper reviewed the literature on bioreduction of AuNPs using various bioagents such as microorganisms and plant tissue. The progress of bioreduction over conventional chemical methods for large scale production of NPs ensued the best way for the synthesis of AuNPs. These NPs are free from toxic chemicals, eco-friendly, simple, one step as well as giving normal reducing agent for optimum stabilization which leads to the green methods.

Table 1 AuNPs synthesis using different bio-agents and their applications

\begin{tabular}{|c|c|c|c|}
\hline Bio-agent & Particle sizes (nm) & Application & Reference \\
\hline Fusarium sp. MMTl & $30.16 \pm 17$ & Catalyst & Guria et al., 2016 \\
\hline Moronga oliefera & $<5$ & Catalyst & Anand et al., 2015 \\
\hline mung bean starch & 10 & Catalyst & Chairam et al., 2015 \\
\hline Salicornia brachiate & $22-$ & Catalyst & Ahmed et al., 2014 \\
\hline Saraca indica & $15-23$ & Catalyst & Dash et al., 2014 \\
\hline Eucommia ulmoides & 16.4 & Catalyst & Guo et al., 2015 \\
\hline Cocos nucifera Linn & 20 & Catalyst & Paul et al., 2014 \\
\hline Xylose & $15 \pm 5$ & Antibacterial & Badwaik et al., 2013 \\
\hline Streptomyces sp. & $4-13$ & Antibacterial & Ibrahim et al., 2016 \\
\hline Ginkgo biloba Linn leaf & & Antibacteral & Velmurugan et al., 2016 \\
\hline Salix alba $L$. & $50-80$ & Antibacterial & Islam, et al., 2015 \\
\hline Diospyros ferrea & $70-90$ & Antibacterial & Ramesh \& Armash, 2015 \\
\hline Chaga mushrooms & $11.0-37.7$ & Antibacterial & Lee et al., 2015 \\
\hline $\begin{array}{l}\text { Plume-ria alba flower extract } \\
\text { (PAFE) }\end{array}$ & $28 \pm 5.6 \& 15.6 \pm 3.4$ & Antibacterial & Mata et al., 2016 \\
\hline Pistacia integerrima & $20-200$ & Antifungal & Islam, et al., 2015 \\
\hline Acorus calamus rhizome & 10 & Antibacterial & Ganesan \& Prabu, 2015 \\
\hline Elettaria cardamomum seeds & 15.2 & Antibacterial & Rajan et al., 2016 \\
\hline Sacha inchi oil & $5-15$ & Photocatalytic & Kumar, at el., 2016 \\
\hline Lagerstroemia speciose & $\leq 40$ & photocatalytic & Choudhary et al., 2016 \\
\hline Pogestemon benghalensis & $10-50$ & Photocatalytic & Poul et al., 2014 \\
\hline N-(4-imidazolyl) Methyl Chitosan & 2.3 & Drug delivery & Nazirov et al., 2016 \\
\hline Arabic gum & $98.65 \pm 1.86$ & Drug delivery & Devi et al., 2015 \\
\hline Genipa americana $L$. & $15-40$ & Anticancer & Kumar at el 2016 \\
\hline Rhus chinensis & $20-40$ & Anticancer & Patil et al., 2016 \\
\hline cassia tora & 57 & Anticancer & Abel et al 2015 \\
\hline Sargassum glaucescens & $3.65 \pm 1.69$ & Anticancer & Ajdari et al 2016 \\
\hline chitosan oligosaccharide & $61.86 \_3.01$ & Anticancer & Manivasagan et al., 2016 \\
\hline Fucoidan & $73-96$ & Anticancer & Manivasagan et al., 2016 \\
\hline Ocimum sanctum Extracts & $1-100$ & & Lee et al., 2016 \\
\hline $\begin{array}{l}\text { Green tea, Zimbro tea and } \\
\text { Green coconut }\end{array}$ & $4-84$ & & Geraldes et al 2016 \\
\hline $\begin{array}{l}\text { Mentha piperita, Melissa } \\
\text { officinalis, and Salvia officinalis }\end{array}$ & $\begin{array}{l}15.1 \pm 10.2,19.5 \pm 24.3 \& \\
55.1 \pm 48.4\end{array}$ & & Dzimitrowicz et al., 2016 \\
\hline Couroupita guianensis Aubl & $26 \pm 11$ & Biomedical & Sathishkumar et al., 2016 \\
\hline 21 different fungi & $<100$ in all & Biomedical & Vágó et al., 2016 \\
\hline Garcinia mangostana & $32.96 \pm 5.25$ & Biomedical & Xin Lee et al., 2016 \\
\hline chitosan oligosaccharide & $115.217 \pm 16.87$ & Biomedical & Yang and Li, 2015 \\
\hline mash of cassava starch & $15-35$ & Biomedical & S. Zeng et al., 2016 \\
\hline Moringa oleifera & $20-60$ & Biomedical & Chakraborty et al., 2013 \\
\hline cassia auricualta & $12-41$ & Biomedical & Venkatachalam et al., 2013 \\
\hline Stevia rebaudiana & $5-20$ & Biomedical & Sadeghi et al., 2015 \\
\hline Proanthocyanidin & $17-29$ & Biomedical & Vinodhini et al., 2014 \\
\hline black cardamom & 50 & Biomedical & Singh et al., 2015 \\
\hline Mentha piperita & $3-26$ & Biomedical & Valencia et al., 2014 \\
\hline
\end{tabular}




\begin{tabular}{llll}
\hline Bio-agent & Particle sizes $\mathbf{( n m )}$ & Application & Reference \\
\hline Stachys lavandulifolia & $34-80$ & Biomedical & Azandehi \& Mogha., 2015 \\
Turbinaria conoides & $6-10)$ & Biomedical & Rajeshkumar et al., 2013 \\
Peltophorum pterocarpum & $10-30$ & Solar Cell & Balamuruga 2016 \\
Tagetes patula & 45 & Sensor & Ateeq et al., 2015 \\
Cerasus serrulata & $5-25$ & Sensor & Karthit et al., 2015 \\
Acacia nilotica twig & $10-50$ & Sensor & Emmanuel et al.., 2014 \\
Rose water & & Sensor & Tabrizi and Varkani, 2014 \\
Gordonia amarae & $15-40$ & Sensor & Bennur et al., 2016 \\
Penicillium aculeatum & 60 & Parasite & Barabadi et al.., 2017 \\
Suaeda monoica leaf & 12.96 & Antioxidant & Rajathi et al., 2014 \\
Stevia rebaudiana & $5-20$ & & Sadeghi et al 2015 \\
mash of cassava & $10-35$ & & Zeng et al 2016 \\
Nerium oleander & $2-10$ & Antioxidant & Tahir et al 2016 \\
Acroscyphus sp. and Sticta sp & $11.36-15.75$ & Antioxidant & Debnath et al 2016 \\
Sambucus nigra L. & $4-26$ & Antioxidant & Opris et al 2016 \\
Lactobacillus kimchicus & $5-30$ & Antioxidant & Markus et al 2016 \\
Piper longum fruit extract & 56 & Antioxidant & Nakala et al 2016 \\
Nepenthes Khasiana & $50-100$ & & Bhau et al 2015 \\
Pterocarpus marsupium & $72-85$ & Antioxidant & Dhamecha et al 2015 \\
Garcinia combogia & & Antioxidant & Nithya \& Jayachitra, 2016 \\
\hline
\end{tabular}

\section{Acknowledgment}

The authors fully acknowledged Tetfund Nigeria, Federal University Kashere and Universiti Sains Malaysia for their support which makes this important research viable and effective.

\section{References}

[1] Lloyd-Hughes, H., et al. 2015. Current and Future Nanotechnology Applications in the Management of Melanoma: A Review. Journal of Nanomedicine \& Nanotechnology. 6(6): 1-12.

[2] Suslick, K. S. 1988. Ultrasound: Its Chemical, Physical, and Biological Effects. VCH Publishers.

[3] Rangari, V., S. Dey, and S. Jeelani. 2016. In-situ Synthesis of Cu Nanoparticles on MWCNTS using Microwave Irradiation. NSTI-Nanotech. 13(1): 140-143.

[4] Shukri, W. N. W. et al. 2015. Synthesize of Gold Nanoparticles with $532 \mathrm{~nm}$ and $1064 \mathrm{~nm}$ Pulsed Laser Ablation. Jurnal Teknologi. 78(3): 267-270.

[5] Archana, J., M. Navaneethan, and Y. Hayakawa. 2016. Morphological Transformation of ZnO Nanoparticle to Nanorods via Solid-solid Interaction at High Temperature Annealing and Functional Properties. Scripta Materialia. 113: 163-166.

[6] Sanchez-Lopez, J. and A. Fernandez. 1998. The Gas-phase Condensation Method for the Preparation of Quantumsized ZnS Nanoparticles. Thin Solid Films. 317(1): 497-499.

[7] Abdullah, N. H., et al. 2016. Synthesis of Zinc Sulphide Nanoparticles from Thermal Decomposition of Zinc N-ethyl Cyclohexyl Dithiocarbamate Complex. Materials Chemistry and Physics. 173: 33-41.

[8] Ng, C. Y., et al. 2014. The Formation of $\mathrm{WO}_{3}$ Nanorods using the Surfactant-assisted Hydrothermal Reaction. Journal of Experimental Nanoscience. 9(1): 9-16.

[9] Bishop, P., et al. 2016. Flame Spray Pyrolysis for the Production of Nanoparticles. NSTI-Nanotech. 13: 15.

[10] Vaquero, F., R. Navarro, and J. Fierro. 2016. Evolution of the Nanostructure of CdS using Solvothermal Synthesis at Different Temperature and Its Influence on the Photoactivity for Hydrogen Production. International Journal of Hydrogen Energy. 41 (27): $11558-11567$.

[11] Moneeb, A. M., et al. 2016. Bimetallic Single-source Precursor for the Synthesis of Pure Nanocrystalline Room
Temperature-stabilized $\beta$-NiMoO 4. Ceramics International. 42(1): 1366-1372.

[12] Umar, M. I. A. et al. 2013. Formation of Gold-coated Multilayer Graphene via Thermal Reduction. Materials Letters. 106: 200-203.

[13] Sodipo, B. K. and A. A. Aziz. 2013. Sonochemical Synthesis of Silica Coated Super Paramagnetic Iron Oxide Nanoparticles. Materials Science Forum.

[14] M. Noruzi. 2015. Biosynthesis of Gold Nanoparticles Using Plant Extracts. Bioprocess Biosyst. Eng. 38(1): 1-14.

[15] Ahmed, S., et al. 2016. A Review on Plants Extract Mediated Synthesis of Silver Nanoparticles for Antimicrobial Applications: A Green Expertise. Journal of Advanced Research. 7(1): 17-28.

[16] Kulkarni, N. and U. Muddapur. 2014. Biosynthesis of Metal Nanoparticles: A Review. Journal of Nanotechnology.

[17] Mittal, A. K., Y. Chisti, and U. C. Banerjee. 2013. Synthesis of Metallic Nanoparticles Using Plant Extracts. Biotechnology Advances. 31 (2): 346-356.

[18] Patra, S., et al. 2015. Green Synthesis, Characterization of Gold and Silver Nanoparticles and Their Potential Application for Cancer Therapeutics. Materials Science and Engineering: C. 53: 298-309.

[19] Mukherjee, S., et al. 2015. A Green Chemistry Approach for the Synthesis of Gold Nanoconjugates that Induce the Inhibition of Cancer Cell Proliferationt Induction of Oxidative Stress and Their in Vivo Toxicity Study. Journal of Materials Chemistry B. 3(18): 3820-3830.

[20] Rajan, A., V. Vilas, and D. Philip. 2015. Studies on Catalytic, Antioxidant, Antibacterial and Anticancer Activities of Biogenic Gold Nanoparticles. Journal of Molecular Liquids. 212: 331-339.

[21] Wenchao, W., et al. 2016. Green Preparation of $\mathrm{Au}$ Nanoparticles for Electrochemical Detection of $\mathrm{H}_{2} \mathrm{O}_{2}$. Journal of Semiconductors. 37(1): 013003.

[22] C. J. Murphy et al. 2008. Gold Nanoparticles in Biology: Beyond Toxicity to Cellular Imaging. Accounts of Chemical Reseach. 41(12):1721-1730.

[23] Sreedhar, B., et al. 2015. Green Synthesis of Gum-acacia Assisted Gold-hydroxyapatite Nanostructurescharacterization and Catalytic Activity. Materials Chemistry and Physics. 153: 23-31.

[24] González-Rubio, G., et al. 2015. Femtosecond Lasercontrolled Tip-to-tip Assembly and Welding of Gold Nanorods. Nano Letters. 15(12): 8282-8288.

[25] A. I. Usman, A. A. Aziz, and O. A. Noqta. 2018. Bio-synthesis of Triangular and Hexagonal Gold Nanoparticles Using 
Palm Oil Fronds' Extracts at Room Temperature. Material Research Express. 5(1).

[26] Zeng, J., et al. 2015. Morphological Control and Plasmonic Tuning of Nanoporous Gold Disks by Surface Modifications. Journal of Materials Chemistry C. 3(2): 247252.

[27] Siti, R. M., et al. 2012. Study on Controlled Size, Shape and Dispersity of Gold Nanoparticles (AuNPs) Synthesized via Seeded-growth Technique for Immunoassay Labeling. Advanced Materials Research. Trans Tech Publ.

[28] Armbrüster, M. and R. Cardoso-Gil. 2015. Synthesis of Supported Ga Nanodrops by a Bottom-up Route. Zeitschrift für anorganische und allgemeine Chemie. 641 (8-9): 1453-1458.

[29] Saranya, K., et al. 2017. In-situ Growth of Cos Nanoparticles onto Electrospun Graphitized Carbon Nanofibers as an Efficient Counter Electrode for DyeSensitized Solar Cells. Journal of Nanoscience and Nanotechnology. 17(1): 398-404.

[30] K. B. Male, J. Li, C. C. Bun, S.-C. Ng, and J. H. T. Luong. 2008. Synthesis and Stability of Fluorescent Gold Nanoparticles by Sodium Borohydride in the Presence of Mono-6-deoxy-6-pyridinium-cyclodextrin Chloride. Journal of Physics and Chemistry. 112: 443-451.

[31] Zhang, Z., et al. 2011. Sodium Citrate: A Universal Reducing Agent for Reduction/Decorationo Graphene Oxide with au Nanoparticles Nano Research. 4(6): 599611.

[32] Ahmed, S. and S. Ikram. 2016. Biosynthesis of Gold Nanoparticles: A Green Approach. Journal of Photochemistry and Photobiology B: Biology. 161: 141-153.

[33] Astruc, D. 2008. Nanoparticles and Catalysis. John Wiley \& Sons.

[34] Steinigeweg, D. and S. Schlücker. 2012. Monodispersity and Size Control in the Synthesis of 20-100 nm Quasispherical Silver Nanoparticles by Citrate and Ascorbic Acid Reduction in Glycerol-water Mixtures. Chemical Communications. 48(69): 8682-8684.

[35] Markus, J., et al. 2016. Intracellular Synthesis of Gold Nanoparticles with Antioxidant Activity by Probiotic Lactobacillus Kimchicus DCY51 T Isolated from Korean Kimchi. Enzyme and Microbial Technology. 95: 85-93.

[36] Derjaguin, B. and L. Landau. 1941. The Theory of Stability of Highly Charged Lyophobic Sols and Coalescence of Highly Charged Particles in Electrolyte Solutions. Acta Physicochim. URSS. 14(58): 633-52.

[37] Overbeek, J. T. G. and E. Verwey. 1948. Theory of the Stability of Lyophobic Colloids: The interaction of Sol Particles Having an Electric Double Layer. Courier Cooperation.

[38] Pugh, R. J., T. Matsunaga, and F. M. Fowkes. 1983. The Dispersibility and Stability of Carbon Black in Media of Low Dielectric Constant. 1. Electrostatic and Steric Contributions to Colloidal Stability. Colloids and Surfaces. 7(3): 183-207.

[39] Raveendran, P., J. Fu, and S.L. Wallen. 2003. Completely "Green" Synthesis and Stabilization of Metal Nanoparticles. Journal of the American Chemical Society. 125(46): 13940-13941.

[40] Lourenco, C., et al. 1996. Steric Stabilization of Nanoparticles: Size and Surface Properties. International Journal of Pharmaceutics. 138(1): 1-12.

[41] Stankus, D. P., et al. 2010. Interactions between Natural Organic Matter and Gold Nanoparticles Stabilized with Different Organic Capping Agents. Environmental Science \& Technology. 45(8): 3238-3244.

[42] Hegedus, L. L. and R. W. McCabe. 1984. Catalyst Poisoning. Vol. 17. Marcel Dekker Incorporated.

[43] Guria, M. K., M. Majumdar, and M. Bhattacharyya. 2016. Green Synthesis of Protein Capped Nano-gold Particle: An Excellent Recyclable Nano-catalyst for the Reduction of Nitro-aromatic Pollutants at Higher Concentration. Journal of Molecular Liquids. 222: 549-557.
[44] Kuroda, K., T. Ishida, and M. Haruta. 2009. Reduction of 4nitrophenol to 4-aminophenol over Au Nanoparticles Deposited on PMMA. Journal of Molecular Catalysis A: Chemical. 298(1): 7-11.

[45] Li, J., C.-y. Liu, and Y. Liu. 2012. Au/graphene Hydrogel: Synthesis, Characterization and Its Use for Catalytic Reduction of 4-nitrophenol. Journal of Materials Chemistry. 22(17). 8426-8430.

[46] Das, S. K., et al. 2013. Bio-inspired Fabrication of Silver Nanoparticles on Nanostructured Silica: Characterization and Application as a Highly Efficient Hydrogenation Catalyst. Green Chemistry. 15(9): 2548-2557.

[47] Li, M. and G. Chen. 2013. Revisiting Catalytic Model Reaction p-nitrophenol/NaBH 4 Using Metallic Nanoparticles Coated on Polymeric Spheres. Nanoscale. 5(23): 11919-11927.

[48] Wu, X., et al. 2014. Green Synthesis and Formation Mechanism of Cellulose Nanocrystal-supported Gold Nanoparticles with Enhanced Catalytic Performance. Environmental Science: Nano. 1(1): 71-79.

[49] Ahmed, K. B. A., et al. 2014. Preparation of Gold Nanoparticles Using Salicornia Brachiata Plant Extract and Evaluation of Catalytic and Antibacterial Activity. Spectrochimica Acta Part A: Molecular and Biomolecular Spectroscopy. 130: 54-58.

[50] Qu, Y., et al. 2016. Biosynthesis of Gold Nanoparticles by Trichoderma sp. WL-Go for Azo Dyes Decolorization. Journal of Environmental Sciences. 56: 79-86.

[51] Mata, R., A. Bhaskaran, and S. R. Sadras. 2016. GreenSynthesized Gold Nanoparticles from Plumeria Alba Flower Extract to Augment Catalytic Degradation of Organic Dyes and Inhibit Bacterial Growth. Particuology. 24: 78-86.

[52] Kumar, B., et al. 2016. One Pot Synthesis and Characterization of Gold Nanocatalyst using Sacha inchi (Plukenetia volubilis) Oil: Green Approach. Journal of Photochemistry and Photobiology B: Biology. 158: 55-60.

[53] Guo, M., et al. 2015. Controllable Biosynthesis of Gold Nanoparticles from a Eucommia ulmoides Bark Aqueous Extract. Spectrochimica Acta Part A: Molecular and Biomolecular Spectroscopy. 142: 73-79.

[54] Nazirov, A., et al. 2016. One-pot Green Synthesis of Luminescent Gold Nanoparticles Using Imidazole Derivative of Chitosan. Carbohydrate Polymers. 151: 649655.

[55] Anand, K., et al. 2015. Agroforestry Waste Moringa Oleifera Petals Mediated Green Synthesis of Gold Nanoparticles and Their Anti-cancer and Catalytic Activity. Journal of Industrial and Engineering Chemistry. 21: 1105-1111.

[56] Chairam, S., W. Konkamdee, and R. Parakhun. 2015. Starch-supported Gold Nanoparticles and Their Use in 4Nitrophenol Reduction. Journal of Saudi Chemical Society. $21(6)$ : 656-663.

[57] Das, S., B. G. Bag, and R. Basu. 2015. Abroma Augusta Linn Bark Extract-mediated Green Synthesis of Gold Nanoparticles and Its Application in Catalytic Reduction. Applied Nanoscience. 5(7): 867-873.

[58] Paul, K., B.G. Bag, and K. Samanta. 2014. Green Coconut (Cocos nucifera Linn) Shell Extract Mediated Size Controlled Green Synthesis of Polyshaped Gold Nanoparticles and Its Application in Catalysis. Applied Nanoscience. 4(6): 769-775.

[59] Dzimitrowicz, A., et al. 2016. Preparation and Characterization of Gold Nanoparticles Prepared with Aqueous Extracts of Lamiaceae Plants and the Effect of Follow-up Treatment with Atmospheric Pressure Glow Microdischarge. Arabian Journal of Chemistry.

[60] Choudhary, B. C., et al. 2016. Photocatalytic Reduction of Organic Pollutant Under Visible Light by Green Route Synthesized Gold Nanoparticles. Journal of Environmental Sciences. 55: 236-246.

[61] Dash, S. S., et al. 2014. Saraca Indica Bark Extract Mediated Green Synthesis of Polyshaped Gold 
Nanoparticles and Its Application in Catalytic Reduction. Applied Nanoscience. 4(4): 485-490.

[62] Mann, J. and M. J. C. 1996. Crabbe, Bacteria and Antibacterial Agents. University Science Books.

[63] Ibrahim, N. A., B. M. Eid, and M. S. Abdel-Aziz. 2016. Green Synthesis of AuNPs for Eco-friendly Functionalization of Cellulosic Substrates. Applied Surface Science. 389: 118125.

[64] Ganesan, R. and H. G. Prabu. 2015. Synthesis of Gold Nanoparticles Using Herbal Acorus Calamus Rhizome Extract and Coating on Cotton Fabric for Antibacterial and UV Blocking Applications. Arabian Journal of Chemistry.

[65] Velmurugan, P., et al. 2016. Gold Nanoparticles Mediated Coloring of Fabrics and Leather for Antibacterial Activity. Journal of Photochemistry and Photobiology B: Biology. 160: 102-109.

[66] Islam, N. U., et al. 2015. Green Synthesis and Biological Activities of Gold Nanoparticles Functionalized with Salix Alba. Arabian Journal of Chemistry.

[67] Bhat, I. U. H., Z. Khanam, and A. Bhat. 2017. Current Trends in the Preparation of Nanoparticles for Drug Delivery, in Engineering Applications of Nanotechnology. Springer. 313-334.

[68] Kumar, B., et al. 2016. One Pot Phytosynthesis of Gold Nanoparticles Using Genipa Americana Fruit Extract and Its Biological Applications. Materials Science and Engineering: C. 62: 725-731.

[69] Rajan, A., A. R. Rajan, and D. Philip. 2016. Elettaria Cardamomum Seed Mediated Rapid Synthesis of Gold Nanoparticles and Its Biological Activities. OpenNano. 2: 1-8.

[70] Ramesh, V. and A. Armash. 2015. An In-vitro Studies on Green Synthesis of Gold Nanoparticles against Pathogens and Cancer Cells. International Journal of Pharmacological Research. 5(10): 250-256.

[71] Devi, P. R., et al. 2015. Synthesis and Characterization of Arabic Gum Capped Gold Nanoparticles for TumorTargeted Drug Delivery. Materials Letters. 139: 241-244.

[72] Patil, M. P. and G.-D. Kim. 2017. Eco-friendly Approach for Nanoparticles Synthesis and Mechanism behind Antibacterial Activity of Silver and Anticancer Activity of Gold Nanoparticles. Applied Microbiology and Biotechnology. 101 (1): 79-92.

[73] Ajdari, Z., et al. 2016. Novel Gold Nanoparticles Reduced by Sargassum Glaucescens: Preparation, Characterization and Anticancer Activity. Molecules. 21 (3): 123.

[74] Manivasagan, P., et al. 2016. Paclitaxel-Loaded Chitosan Oligosaccharide-stabilized Gold Nanoparticles as Novel Agents for Drug Delivery and Photoacoustic Imaging of Cancer Cells. International Journal of Pharmaceutics. 511(1): 367-379.

[75] Manivasagan, P., et al. 2016. Doxorubicin-loaded Fucoidan Capped Gold Nanoparticles for Drug Delivery and Photoacoustic Imaging. International Journal of Biological Macromolecules. 91: 578-588.

[76] Abel, E. E., P. R. J. Poonga, and S. G. Panicker. 2016. Characterization and in Vitro Studies on Anticancer, Antioxidant Activity against Colon Cancer Cell Line of Gold Nanoparticles Capped with Cassia Tora SM Leaf Extract. Applied Nanoscience. 6(1): 121-129.

[77] Sathishkumar, G., et al. 2016. Cannonball Fruit (Couroupita guianensis, Aubl.) Extract Mediated Synthesis of Gold Nanoparticles and Evaluation of Its Antioxidant Activity. Journal of Molecular Liquids. 215: 229-236.

[78] Vágó, A., et al. 2016. One-step Green Synthesis of Gold Nanoparticles by Mesophilic Filamentous Fungi. Chemical Physics Letters. 645: 1-4.

[79] Xin Lee, K., et al. 2016. Green Synthesis of Gold Nanoparticles Using Aqueous Extract of Garcinia mangostana Fruit Peels. Journal of Nanomaterials.

[80] Zeng, S., et al. 2016. Biological Synthesis of Au Nanoparticles Using Liquefied Mash of Cassava Starch and Their Functionalization for Enhanced Hydrolysis of
Xylan by Recombinant Xylanase. Bioprocess and Biosystems Engineering. 39(5): 785-792.

[81] Sadeghi, B., M. Mohammadzadeh, and B. Babakhani. 2015. Green Synthesis of Gold Nanoparticles Using Stevia Rebaudiana Leaf Extracts: Characterization and Their Stability. Journal of Photochemistry and Photobiology B: Biology. 148: 101-106.

[82] Khademi-Azandehi, P. and J. Moghaddam. 2015. Green Synthesis, Characterization and Physiological Stability of Gold Nanoparticles from Stachys Lavandulifolia Vahl Extract. Particuology. 19: 22-26.

[83] Chakraborty, A., et al. 2013. Moringa Oleifera Leaf Extract Mediated Green Synthesis of Stabilized Gold Nanoparticles. Journal of Bionanoscience. 7(4): 415-419.

[84] Yang, N. and W.-H. Li. 2015. Preparation of Gold Nanoparticles Using Chitosan Oligosaccharide as a Reducing and Capping Reagent and Their in Vitro Cytotoxic Effect on Human Fibroblasts Cells. Materials Letters. 138: 154-157.

[85] Vinodhini, A., et al. 2014. Cardioprotective potential of biobased gold nanoparticles. Colloids and Surfaces $B$ : Biointerfaces. 117: 480-486.

[86] Venkatachalam, M., et al. 2013. Functionalization of Gold Nanoparticles as Antidiabetic Nanomaterial. Spectrochimica Acta Part A: Molecular and Biomolecular Spectroscopy. 116:331-338.

[87] Rajeshkumar, S., et al. 2013. Seaweed-mediated Synthesis of Gold Nanoparticles Using Turbinaria Conoides and Its Characterization. Journal of Nanostructure in Chemistry. $3(1): 1-7$

[88] Singh, A. K. and O. Srivastava. 2015. One-step Green Synthesis of Gold Nanoparticles using Black Cardamom and Effect of $\mathrm{pH}$ on its Synthesis. Nanoscale Research Letters. 10(1): 353.

[89] Valencia, G. A., et al. 2014. Synthesis and Characterisation of Gold Nanoparticles Using Mentha Piperita Leaf Extract: A Green, Non-Toxic and Rapid Method. International Journal of Nano and Biomaterials. 5(2-3): 181-192.

[90] Balamurugan, M., S. Kaushik, and S. Saravanan. 2016. Green Synthesis of Gold Nanoparticles by Using Peltophorum Pterocarpum Flower Extracts. Nano Biomedicine \& Engineering. 8(4).

[91] Ateeq, M., et al. 2015. Green Synthesis and Molecular Recognition Ability of Patuletin Coated Gold Nanoparticles. Biosensors and Bioelectronics. 63: 499-505.

[92] Karthik, R., et al. 2016. Phyto Mediated Biogenic Synthesis of Gold Nanoparticles Using Cerasus Serrulata and its Utility in Detecting Hydrazine, Microbial Activity and DFT Studies. Journal of Colloid and Interface Science. 468: 163175.

[93] Barabadi, H., et al. 2017. Green Chemical Synthesis of Gold Nanoparticles by Using Penicillium Aculeatum and Their Scolicidal Activity against Hydatid Cyst Protoscolices of Echinococcus Granulosus. Environmental Science and Pollution Research. 1-11.

[94] Emmanuel, R., et al. 2014. Green Synthesis of Gold Nanoparticles for Trace Level Detection of a Hazardous Pollutant (Nitrobenzene) Causing Methemoglobinaemia. Journal of Hazardous Materials. 279: 1 17-124.

[95] Tabrizi, M. A. and J. N. Varkani. 2014. Green Synthesis of Reduced Graphene Oxide Decorated with Gold Nanoparticles and Its Glucose Sensing Application. Sensors and Actuators B: Chemical. 202: 475-482.

[96] Bennur, T., et al. 2016. Biogenic Gold Nanoparticles from the Actinomycete Gordonia Amarae: Application in Rapid Sensing of Copper Ions. Sensors and Actuators B: Chemical. 233: 684-690.

[97] Chen, A. Y. et al. 2016. Entacapone is an Antioxidant More Potent than Vitamin $C$ and Vitamin E for Scavenging of Hypochlorous Acid and Peroxynitrite, and the Inhibition of Oxidative Stress-induced Cell Death. Medical Science Monitor. International Medical Journal of Experimental and Clinical Research. 22: 687. 
[98] Tahir, K. et al. 2015. Nerium Oleander Leaves Extract Mediated Synthesis of Gold Nanoparticles and Its Antioxidant Activity. Materials Letters. 156: 198-201.

[99] Debnath, R., et al. 2016. Biogenic Synthesis of Antioxidant, Shape Selective Gold Nanomaterials Mediated by High Altitude Lichens. Materials Letters. 169: 58-61.

[100] Opris, R. et al. 2017. The Effect of Sambucus nigra L. Extract and Phytosinthesized Gold Nanoparticles on Diabetic Rats. Colloids and Surfaces B: Biointerfaces. 150: 192-200.

[101] Nakkala, J. R., R. Mata, and S. R. Sadras. 2016. The Antioxidant and Catalytic Activities of Green Synthesized
Gold Nanoparticles from Piper Longum Fruit Extract. Process Safety and Environmental Protection. 100: 288294.

[102] Dhamecha, D., et al. 2016. Green Synthesis of Gold Nanoparticles Using Pterocarpus Marsupium: Characterization and Biocompatibility Studies. Particulate Science and Technology. 34(2): 156-164.

[103] Nithya, B. and A. Jayachitra. 2016. Exertion of Gold Nanoparticles Synthesis in Extract of Garcinia combogia Leaves, Evaluation of its Total Phenolic Content and its Distinct Antioxidant Activity. Int. J. Pure App. Biosci. 4(4): 69-76. 